Article

\title{
Silica-Coated Magnetic Iron Oxide Nanoparticles Grafted onto Graphene Oxide for Protein Isolation
}

\author{
Xuan-Hung Pham ${ }^{1}{ }^{\mathbb{D}}$, Eunil Hahm ${ }^{1}$, Hyung-Mo Kim ${ }^{1}$, Byung Sung Son ${ }^{1}$, Ahla Jo ${ }^{1}$, \\ Jaehyun An ${ }^{1}$, Tuong An Tran Thi ${ }^{2}$, Dinh Quan Nguyen ${ }^{2}$ and Bong-Hyun Jun ${ }^{1, *(D)}$ \\ 1 Department of Bioscience and Biotechnology, Konkuk University, Seoul 05029, Korea; \\ phamricky@gmail.com (X.-H.P.); greenice@konkuk.ac.kr (E.H.); hmkim0109@konkuk.ac.kr (H.-M.K.); \\ imsonbs@konkuk.ac.kr (B.S.S.); iamara0421@konkuk.ac.kr (A.J.); ghj4067@konkuk.ac.kr (J.A.) \\ 2 Laboratory of Biofuel and Biomass Research, VNU-HCMU University of Technology, 268 Ly Thuong Kiet \\ street, district 10, Ho Chi minh 700000, Vietnam; trantuongan81@gmail.com (T.A.T.T.); \\ ndquan@hcmut.edu.vn (D.Q.N.) \\ * Correspondence: bjun@konkuk.ac.kr; Tel.: +82-2-450-0521
}

Received: 28 November 2019; Accepted: 6 January 2020; Published: 8 January 2020

check for updates

\begin{abstract}
In this study, silica-coated magnetic iron oxide nanoparticles $\left(\mathrm{MNPs} @ \mathrm{SiO}_{2}\right)$ were covalently conjugated onto graphene oxide $\left(\mathrm{GO} / \mathrm{MNP}_{\mathrm{SiO}}\right)$ for protein isolation. First, MNPs were precisely coated with a silica layer on the surface by using the reverse microemulsion method, followed by incubation with 3-glycidyloxypropyltrimethoxysilane (GPTS) to produce the GPTS-functionalized MNPs@SiO 2 (GPTS-coated MNPs@SiO 2 ) that display epoxy groups on the surface. The silica shell on the MNPs was optimized at $300 \mu \mathrm{L}$ of Igepal ${ }^{\circledR} \mathrm{CO}-520,5 \mathrm{mg}$ of MNP, $100 \mu \mathrm{L}$ of TEOS, $100 \mu \mathrm{L}$ of $\mathrm{NH}_{4} \mathrm{OH}$ and 3\% of 3-glycidyloxypropyltrimethoxysilane (GPTS). Simultaneously, polyethyleneimine (PEI) was covalently conjugated to GO to enhance the stability of GO in aqueous solutions and create the reaction sites with epoxy groups on the surface of GPTS-coated ${\mathrm{MNP} @ S i O_{2}}_{2}$. The ratio of PEI grafted GO and GPTS-coated $\mathrm{MNP} @ S i O_{2}$ (GO/MNP ratio) was investigated to produce GO/MNPs@SiO${ }_{2}$ with highly saturated magnetization without aggregation. As a result, the GO/MNP ratio of 5 was the best condition to produce the $\mathrm{GO} / \mathrm{MNP} @ S i O_{2}$ with $9.53 \mathrm{emu} / \mathrm{g}$ of saturation superparamagnetization at a magnetic field of $2.0(\mathrm{~T})$. Finally, the GO/MNPs@SiO ${ }_{2}$ were used to separate bovine serum albumin (BSA) to investigate its protein isolation ability. The quantity of BSA adsorbed onto $1 \mathrm{mg}$ of GO/MNP@SiO ${ }_{2}$ increased sharply over time to reach $628 \pm 9.3 \mu \mathrm{g} / \mathrm{mg}$ after $15 \mathrm{~min}$, which was 3.5-fold-higher than that of GPTS-coated ${\mathrm{MNP} @ S i O_{2}}_{2}$. This result suggests that the GO/MNP@SiO nanostructure can be used for protein isolation.
\end{abstract}

Keywords: graphene oxide; superparamagnetic iron oxide nanoparticles; reverse microemulsion; silica-coated superparamagnetic nanoparticle; superparamagnetic nanoparticle embedded graphene oxide; protein isolation

\section{Introduction}

Graphene oxide (GO) has attracted significant attention in recent decades due to its attractive properties, such as its large surface area, high electron transport capability, elasticity, thermal conductivity, mechanical strength, and tunable optical properties [1]. As a result, graphene oxide is utilized in many applications, such as catalysis [2], sensing [3], energy [4], drug delivery [5], and biomedical applications-deep brain stimulators [6], blood glucose sensors [7], tissue engineering [8,9], gene therapy [10], cell imaging [11], cancer therapies [12], and to differentiate and image stem cells [13]. However, the separation of GO from solution is a time-consuming and complicated process [14]. 
Magnetic iron oxide nanoparticles (MNPs) with diameters of $20 \mathrm{~nm}$ or less are superparamagnetic [15] and have been attracted due to their superparamagnetism, high field irreversibility, high saturation field, extra anisotropy contributions or shifted loops after field cooling non-toxicity and biocompatibility $[16,17]$. As a result, the MNP was applied in various biomedical applications such as drug delivery [18,19], chemotherapy [17] and bioimaging [15]. There are several routes for chemical synthesis of superparamagnetic MNP: co-precipitation, microemulsion, sonochemical, hydrothermal and so on [17]. Among these methods, the synthesis of MNP by coprecipitation is facile and can be easily scaled up. However, the size of MNP is widely distributed and agglomerated because of Oswald ripening [17]. The MNP synthesized by microemulsion (water-in-oil) is formed inside of water droplets and can be well controlled in size by controlling the size of these water droplets in microemulsion system. However, these NPs may not be useful for drug delivery purposes [17]. In addition, the synthesis of MNP by sonochemical was limited by large-scale synthesis [17]. The hydrothermal method is reported to produce MNPs of uniform sizes and can easily be scaled up [17]. However, the magnetic force of each single MNP is too weak under the externally applied magnetic field and limiting their practical application $[15,17,20,21]$.

Recently, the combination of GO with nanoparticles, forming graphene-nanoparticle hybrid structures, has been shown to offer many additional unique physicochemical properties that are markedly advantageous for applications, such as supercapacitors, electrode materials, drug carriers, and bioimaging [22]. Among these graphene-nanoparticle hybrid materials, MNP-decorated GO nanocomposites (GO-MNP) have been synthesized by several groups for removing hazard materials [23-25], sensing/biosensing [26-30], enrichment and adsorption of peptide or protein [31,32], sample manipulation for bio-separation [30,33], bioimaging [34] and drug delivery [35,36] applications. GO-MNP nanocomposites are formed through in situ reduction of iron salt precursors $[37,38]$ or assembly of the MNPs on the GO surface $[39,40]$. The former approach, however, is challenging, as there is minimal control over the size, size distribution, and location of MNPs on the GO sheets. The latter approach enables well-controlled size, size distribution, morphology, and controlled decoration ratio on the edge of the GO sheets [40]. Ye et al. prepared GO/MNP nanocomposite by simply drop-wise adding MNP into GO solution through electrostatic interaction [31]. The covalent conjugation of MNP and GO were reported for preparing GO/MNP using "click" chemistry by Zhang et al. [23]. The surface modification of MNP was; however, complicated. In addition, Zhang et al. covalently bound MNPs to a reduced GO sheet by modifying the MNP with hydrophilic 2,3-dimercaptosuccinnic acid (DMSA), followed by assembly onto GO-grafted PEI sheets [40]. However, the mechanism of DMSA adsorption onto the MNP remains unclear. In addition, the GO-MNP composites agglomerated, resulting in gradual precipitation from their aqueous suspension [35].

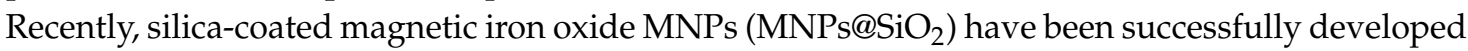
and used in biomedical applications, such as macromolecular separation [41]. The silica layer not only improves the stability in aqueous solution, but also facilitates surface modification with different functional groups [42,43]. MNPs@SiO 2 can be prepared by several methods, such as Stöber [44] or

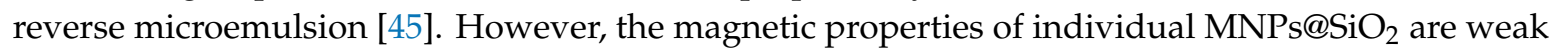
due to an excess of amorphous silica that lowers the individual magnetic force, thereby limiting their practical application $[20,21]$. To overcome the weak magnetic force of $\mathrm{MNP}_{\mathrm{SiO}}$ and the difficult separation of GO, we develop a new nanomaterial by conjugating $\mathrm{MNP}_{\mathrm{SiO}}$ to GO platform by covalent bonding in this study. A reverse microemulsion method was used to control the silica coating on the MNPs to produce $\mathrm{MNPs} @ \mathrm{SiO}_{2}$ with highly saturated magnetization. $\mathrm{MNPs} @ \mathrm{SiO}_{2}$ were covalently bound to GO to form the MNP functionalized GO. The presence of GO as a platform for conjugating to $\mathrm{MNPs} @ \mathrm{SiO}_{2}$ facilitates the isolation and separation of biomaterial from solution. In this process, PEI was first covalently conjugated to GO to enhance the stability of GO in aqueous solutions. MNPs were precisely coated with a silica layer on the surface, followed by incubation

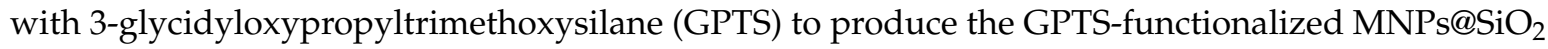
(GPTS-coated MNPs@SiO ${ }_{2}$ ) that display epoxy groups on the surface. GPTS-coated $\mathrm{MNPs} @ \mathrm{SiO}_{2}$ were 
conjugated onto the surface of PEI grafted GO to produce GO/MNPs@SiO $\mathrm{Si}_{2}$ with highly saturated magnetization. Finally, the GO/MNPs@SiO ${ }_{2}$ were used to separate bovine serum albumin (BSA) to investigate its protein isolation ability.

\section{Materials and Methods}

\subsection{Chemicals and Materials}

Graphene oxide (GO) was purchased from Graphene Laboratory Inc. (Ronkonkoma, NY, USA). Cyclohexane, Igepal ${ }^{\circledR}$ CO-520 (Igepal, $\mathrm{M}_{n}=441$ ), branched polyethyleneimine (PEI, 25k), $\mathrm{N}$-Hydroxysuccinimide (NHS), N-(3-Dimethylaminopropyl)- $\mathrm{N}^{\prime}$-ethyl carbodiimide hydrochloride (EDC), tetraethyl orthosilicate (TEOS), 3-Glycidyloxypropyltrimethoxysilane (GPTS), ethyl alcohol $(\mathrm{EtOH})$, bovine serum albumin (BSA) and phosphate buffer saline (PBS) were purchased from Sigma-Aldrich (St. Louis, MO, USA) and used without further purification. $\mathrm{Fe}_{3} \mathrm{O}_{4}$ nanoparticles (MNP) with superparamagnetic property were purchased from Ocean Nanotech (San Diego, CA, USA). Aqueous ammonium hydroxide $\left(\mathrm{NH}_{4} \mathrm{OH}, 27 \%\right)$ was purchased from Daejung (Siheung, Korea). DI water was purified using a Direct-Q Millipore water purification system (Sam Woo S\&T Co., Ltd., Seongnam, Gyeonggi-do, Korea.)

\subsection{Characterization}

Transmission electron microscope (TEM) images of the sample were taken using a Libra 120 field-emission transmission electron microscope (Carl Zeiss, German) with a maximum accelerated voltage of $120 \mathrm{kV}$. Optical properties of our materials were observed by an Optizen POP UV/Vis Spectrometer (Mecasys, Seoul, Korea). Magnetic measurement was carried out using a PPMS-9 vibrating sample magnetometer (Quantum Design, San Diego, CA, USA) at room temperature. Attenuated total reflection-Fourier transform infrared spectra of our materials was recorded on a Nicolet ${ }^{\mathrm{TM}}$ iS $^{\mathrm{TM}} 50$ Fourier transform infrared spectroscopy (FTIR) Spectrometer (Thermo Fisher, Waltham, MA, USA).

\subsection{Optimized Preparation of Silica-Coated Magnetic $\mathrm{Fe}_{3} \mathrm{O}_{4}$ Nanoparticles}

\subsubsection{Effect of Igepal ${ }^{\circledR} \mathrm{CO}-520$ Volume on Silica-Coated Magnetic $\mathrm{Fe}_{3} \mathrm{O}_{4}$ Nanoparticles}

MNPs were coated with silica by the reverse microemulsion method. Various volumes of Igepal ${ }^{\circledR} \mathrm{CO}-520(0.1$ to $5 \mathrm{~mL}$ ) were added into $11 \mathrm{~mL}$ cyclohexane and sonicated for $10 \mathrm{~min}$. Subsequently, $5 \mathrm{mg}$ of MNPs in chloroform was added to the solution and mixed for several minutes to disperse the MNPs into the Igepal ${ }^{\circledR} \mathrm{CO}-520$ solution. Next, $\mathrm{NH}_{4} \mathrm{OH}(100 \mu \mathrm{L})$ and TEOS $(100 \mu \mathrm{L})$ were added drop-wise, and the mixture was incubated for $16 \mathrm{~h}$ at $25^{\circ} \mathrm{C}$. Next, the mixture was precipitated by adding $20 \mathrm{~mL}$ EtOH and centrifuged at $8500 \mathrm{rpm}$ for $30 \mathrm{~min}$. The precipitate was washed five times with EtOH. Finally, the MNPs@SiO $\mathrm{S}_{2}$ were re-dispersed into EtOH to obtain a $1 \mathrm{mg} / \mathrm{mL} \mathrm{MNP}_{\mathrm{SSiO}}$ solution.

\subsubsection{Effect of Quantity of MNPs on Silica-Coated Magnetic $\mathrm{Fe}_{3} \mathrm{O}_{4}$ Nanoparticles}

A volume of $0.3 \mathrm{~mL}$ of Igepal ${ }^{\circledR} \mathrm{CO}-520$ was added into $11 \mathrm{~mL}$ cyclohexane and sonicated for $10 \mathrm{~min}$. Subsequently, various quantities of MNPs in chloroform $(1,3,5,7$ and $10 \mathrm{mg})$ were added to the solution and mixed for several minutes to disperse the MNPs into the Igepal ${ }^{\circledR} \mathrm{CO}-520$ solution. Next, $\mathrm{NH}_{4} \mathrm{OH}(100 \mu \mathrm{L})$ and TEOS $(100 \mu \mathrm{L})$ were added drop-wise, and the mixture was incubated for $16 \mathrm{~h}$ at $25{ }^{\circ} \mathrm{C}$. Next, the mixture was precipitated by adding $20 \mathrm{~mL}$ EtOH and centrifuged at $8500 \mathrm{rpm}$ for $30 \mathrm{~min}$. The precipitate was washed five times with EtOH. Finally, the $\mathrm{MNPs}_{\mathrm{SSiO}}$ were re-dispersed into $\mathrm{EtOH}$ to obtain a $1 \mathrm{mg} / \mathrm{mL} \mathrm{MNP} @ S i O_{2}$ solution.

\subsubsection{Effect of TEOS Volume on Silica-Coated Magnetic $\mathrm{Fe}_{3} \mathrm{O}_{4}$ Nanoparticles}

A volume of $0.3 \mathrm{~mL}$ of Igepal ${ }^{\circledR} \mathrm{CO}-520$ was added into $11 \mathrm{~mL}$ cyclohexane and sonicated for $10 \mathrm{~min}$. Subsequently, $5 \mathrm{mg}$ of MNPs in chloroform was added to the solution and mixed for several min to 
disperse the MNPs into the Igepal ${ }^{\circledR} \mathrm{CO}-520$ solution. Next, $\mathrm{NH}_{4} \mathrm{OH}(100 \mu \mathrm{L})$ and various volumes of TEOS $(10,50,100,150$ and $200 \mu \mathrm{L})$ were added drop-wise, and the mixture was incubated for $16 \mathrm{~h}$ at $25{ }^{\circ} \mathrm{C}$. Next, the mixture was precipitated by adding $20 \mathrm{~mL} \mathrm{EtOH}$ and centrifuged at $8500 \mathrm{rpm}$ for $30 \mathrm{~min}$. The precipitate was washed five times with $\mathrm{EtOH}$. Finally, the $\mathrm{MNPs}_{\mathrm{S}} \mathrm{SiO}_{2}$ were re-dispersed into $\mathrm{EtOH}$ to obtain a $1 \mathrm{mg} / \mathrm{mL} \mathrm{MNP@SiO} 2$ solution.

\subsubsection{Effect of GPTS Concentration on Silica-Coated Magnetic $\mathrm{Fe}_{3} \mathrm{O}_{4}$ Nanoparticles}

MNPs@SiO ${ }_{2}$ were re-dispersed into dimethylfuran (DMF) to obtain a $1 \mathrm{mg} / \mathrm{mL} \mathrm{MNP@SiO}{ }_{2}$

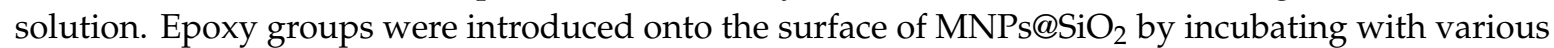

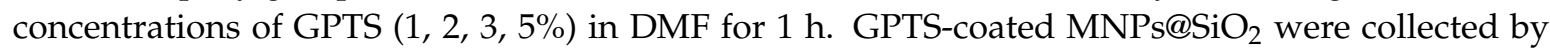
centrifuging at 15,000 rpm for $30 \mathrm{~min}$, washed several times, and dispersed into DMF to obtain a $5 \mathrm{mg} / \mathrm{mL}$ GPTS-coated ${\mathrm{MNP} @ S i \mathrm{O}_{2}}_{2}$ solution.

\subsection{Preparation of Graphene Oxide Grafted with Polyethyleneimine (PEI grafted GO)}

GO (2.5 mg in $0.5 \mathrm{~mL} \mathrm{H}_{2} \mathrm{O}$ ) was added to a PEI solution ( $400 \mu \mathrm{g}$ PEI in $9.5 \mathrm{~mL} \mathrm{H}_{2} \mathrm{O}$ ) to obtain a final concentration of $40 \mu \mathrm{g} / \mathrm{mL}$ of PEI. The mixture was sonicated for $30 \mathrm{~min}$ and incubated at $60^{\circ} \mathrm{C}$ for $12 \mathrm{~h}$. Then, the mixture was centrifuged at $17,000 \mathrm{rpm}$ for $1 \mathrm{~h}$, and the precipitate was washed five times with PBS solution to remove the unbound PEI. PEI-adsorbed to GO was re-dispersed in a $0.5 \mathrm{~mL}$ PBS.

EDC (20 mg) and NHS (14 mg) in $0.5 \mathrm{~mL}$ PBS were added into the PEI-adsorbed GO solution to activate the carboxyl groups for $1 \mathrm{~h}$. PEI $(20 \mathrm{mg})$ was added to the mixture. The mixture was incubated for $2 \mathrm{~h}$ at room temperature to conjugate PEI onto the GO surface. An ethanolamine solution $(100 \mu \mathrm{L}$, $1 \mathrm{M}$ ) was added to the mixture and incubated for $1 \mathrm{~h}$ to block the unreacted carboxyl groups. PEI grafted GO was collected by centrifugation at 17,000 rpm for $30 \mathrm{~min}$ and re-dispersed in $5 \mathrm{~mL}$ PBS.

\subsection{Preparation of Silica-Coated Magnetic Nanoparticles Grafted onto Graphene Oxide (GO/MNP@SiO2)}

GPTS-coated MNP@SiO 2 solution $(250 \mu \mathrm{g})$ was added to the PEI-grafted GO solution (250 to $2500 \mu \mathrm{g})$ and vigorously mixed for $2 \mathrm{~h}$ at $25^{\circ} \mathrm{C}$. An ethanolamine solution $(100 \mu \mathrm{L}, 1.0 \mathrm{M})$ was added to the mixture and incubated for $1 \mathrm{~h}$ to block the unreacted epoxy groups. GO/MNP@SiO $\mathrm{S}_{2}$ was collected by centrifugation 3 times at $8500 \mathrm{rpm}$ for $15 \mathrm{~min}$, followed by applying a magnetic force for $5 \mathrm{~min}$ and washing 5 times with PBS.

\subsection{BSA Isolation by GO/MNP@SiO 2}

BSA was adsorbed into GO/MNP@SiO ${ }_{2}$ by incubation. Briefly, $1 \mathrm{mg}$ of GO/MNP@SiO 2 in $\mathrm{PBS}$ was incubated with $1 \%$ BSA in PBS buffer $(100 \mu \mathrm{L})$ for $2 \mathrm{~h}$. BSA adsorbed GO/MNP@SiO ${ }_{2}$ was collected by applying a magnetic separator. The BSA adsorbed GO/MNP@SiO ${ }_{2}$ was washed several times with PBS, and the supernatant was collected and diluted to $50 \mathrm{~mL}$. The concentration of BSA in supernatant

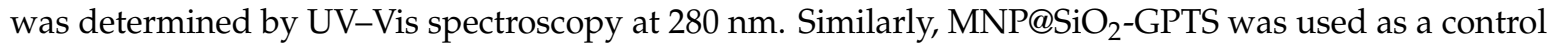
sample for BSA isolation.

\section{Results and Discussion}

Superparamagnetic MNPs $(\sim 20 \mathrm{~nm})$ were coated with a silica layer using the reverse microemulsion method. The surface of ${\mathrm{MNP} @ S i \mathrm{O}_{2}}_{2}$ was modified with epoxy groups by incubating them with GPTS (MNPs@ $\mathrm{SiO}_{2}$-GPTS). Simultaneously, PEI was first adsorbed on the GO surface for $24 \mathrm{~h}$ at $60{ }^{\circ} \mathrm{C}$, and stabilized the GO surface so that GO can be well dispersed in an aqueous solution (PEI adsorbed GO). Subsequently, the $\mathrm{COOH}$ groups of the GO surface were coupled with the $\mathrm{NH}_{2}$ groups of PEI

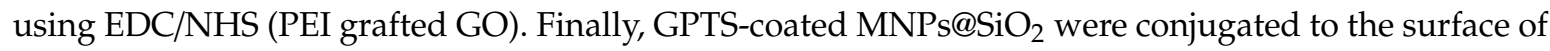
PEI grafted $\mathrm{GO}$ by coupling the PEI $\mathrm{NH}_{2}$ groups with the epoxy groups on the surface of GPTS-coated $\mathrm{MNP} @ S i O_{2}$, producing GO/MNP@SiO 2 nanocomposites (Figure 1). 


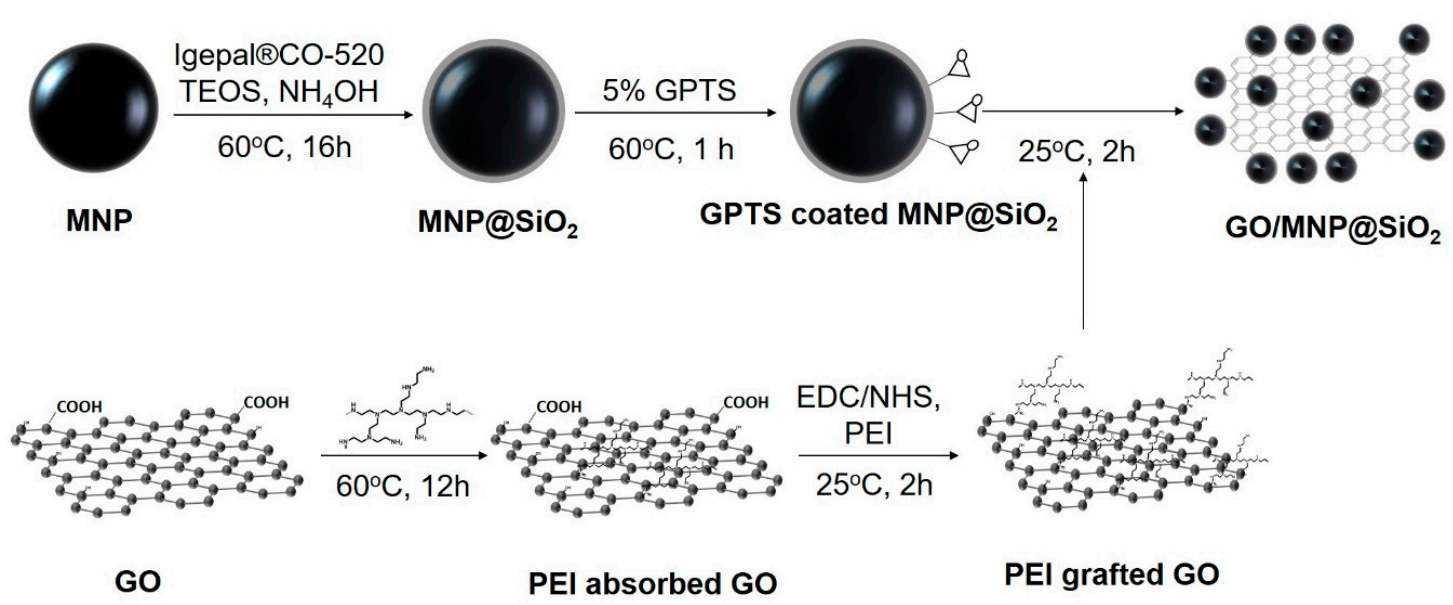

Figure 1. Schematic of the preparation of silica-coated superparamagnetic iron oxide nanoparticles grafted graphene oxide nanostructures (GO/MNP@SiO $\left.{ }_{2}\right)$.

\subsection{Optimized Preparation of Silica-Coated Magnetic Nanoparticles (MNPs@SiO $\left.{ }_{2}\right)$}

The coating of the silica layer on the MNP surface via the reverse microemulsion method was optimized by varying experimental parameters such as Igepal CO-520 and TEOS volumes, as well as the number density of MNPs.

\subsubsection{Effect of Igepal ${ }^{\circledR} \mathrm{CO}-520$ Volume on Silica-Coated Magnetic $\mathrm{Fe}_{3} \mathrm{O}_{4}$ Nanoparticles}

In this study, the average diameter of superparamagnetic MNPs is $20.6 \pm 1.0 \mathrm{~nm}(\mathrm{n}=20)$ as determined by ImageJ software analysis on TEM images (Figure 2a(i)). Figure 2a(ii-viii) shows TEM images of MNPs@SiO 2 synthesized with varying Igepal ${ }^{\circledR} \mathrm{CO}-520$ volumes $(100$ to $5000 \mu \mathrm{L})$. At a low surfactant volume $(100 \mu \mathrm{L})$, aggregated core-free silica nanoparticles and superparamagnetic $\mathrm{MNP@SiO} 2$ were formed in Figure 2a(ii). According to the previous report, Igepal ${ }^{\circledR} \mathrm{CO}-520$ self-assembles into micelles in cyclohexane due to its hydrophilic groups (Figure S1). The oleic acid that adsorbed on the surface of superparamagnetic MNP during synthesis was exchanged to Igepal ${ }^{\circledR}$ CO-520 in the cyclohexane [46]. Therefore, at low volume Igepal ${ }^{\circledR}$ CO-520 cannot self-assemble

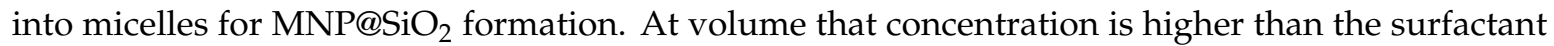
$\mathrm{CMC}\left(200\right.$ to $500 \mu \mathrm{L}$ ), superparamagnetic ${\mathrm{MNPs} @ S i \mathrm{O}_{2}}_{2}$ were well obtained with diameters of $30.2 \pm 1.7$, $37.7 \pm 1.4,37.4 \pm 1.5$, and $32.1 \pm 1.8 \mathrm{~nm}$ with $200,300,400$, and $500 \mu \mathrm{L}$ of surfactant, respectively (Figure $2 b)$. However, Igepal ${ }^{\circledR} \mathrm{CO}-520$ micelles could fuse at extremely high volumes $(>2500 \mu \mathrm{L})$ [47], resulting in aggregated $\mathrm{MNPs} @ \mathrm{SiO}_{2}$ and core-free silica nanoparticles (bare $\mathrm{SiO}_{2} \mathrm{NPs}$ ). As a result, $300 \mu \mathrm{L}$ of Igepal ${ }^{\circledR} \mathrm{CO}-520$ was applied for further study. 
(a)

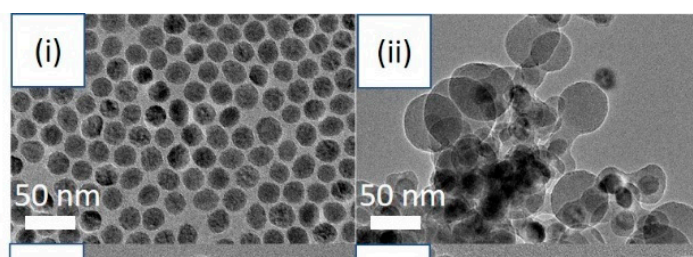

(v) 980

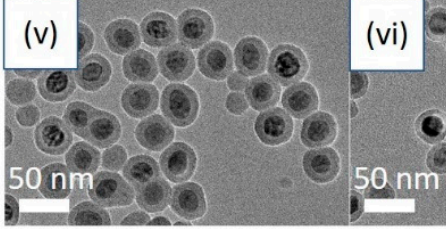

(vi)
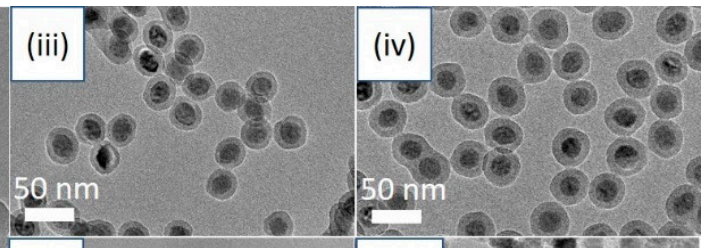

(vii)

(viii)
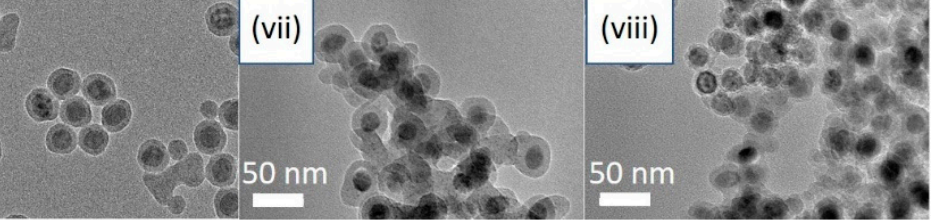

(b)

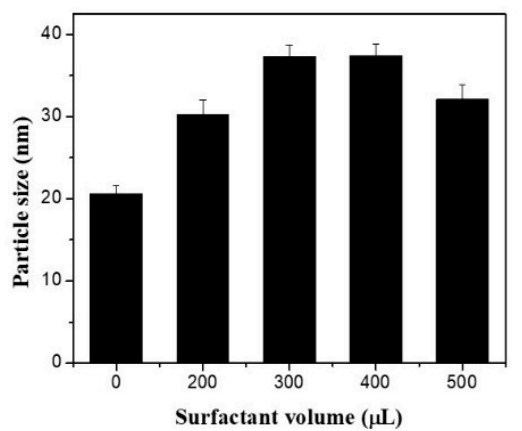

(c)

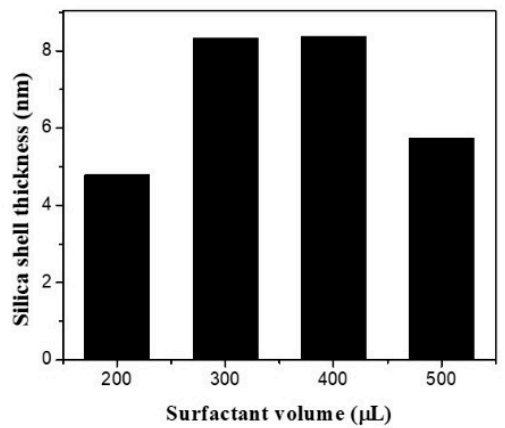

Figure 2. Effects of reverse microemulsion conditions on the silica coating of the magnetic nanoparticles. (a) Transmission electron microscope (TEM) images, (b) particle size and (c) silica shell thickness of ${\mathrm{MNP} @ S i O_{2}}_{2}$ synthesized at different Igepal ${ }^{\circledR} \mathrm{CO}-520$ surfactant volumes: (i) $0 \mu \mathrm{L}$, (ii) $100 \mu \mathrm{L}$, (iii) 200 $\mu \mathrm{L}$, (iv) $300 \mu \mathrm{L}$, (v) $400 \mu \mathrm{L}$, (vi) $500 \mu \mathrm{L}$, (vii) $2500 \mu \mathrm{L}$, and (viii) $5000 \mu \mathrm{L}$ in the presence of $5 \mathrm{mg}$ of MNPs, $100 \mu \mathrm{L}$ of TEOS, and $100 \mu \mathrm{L}$ of $\mathrm{NH}_{4} \mathrm{OH}$.

\subsubsection{Effect of Quantity of MNPs on Silica-Coated Magnetic $\mathrm{Fe}_{3} \mathrm{O}_{4}$ Nanoparticles}

To obtain superparamagnetic $\mathrm{MNPs} @ \mathrm{SiO}_{2}$ without the presence of bare $\mathrm{SiO}_{2} \mathrm{NPs}$, the ratio of $\mathrm{MNP}$ and micelle number density is a critical parameter. Varying the MNP quantity (1 to $10 \mathrm{mg}$ ) revealed that bare $\mathrm{SiO}_{2} \mathrm{NPs}$ were produced with $1 \mathrm{mg}$ of MNPs (Figure 3). The diameter of $\mathrm{MNPs} @ \mathrm{SiO}_{2}$ when $1 \mathrm{mg}$ of MNP was used equaled $46.3 \pm 1.1 \mathrm{~nm}$, which is larger than the diameter of $37.7 \pm 1.4 \mathrm{~nm}$ when $5 \mathrm{mg}$ of MNP was used. This result indicates that the silica layer of MNPs is thicker and TEOS was excess in solution at $1 \mathrm{mg}$ of MNP than at $5 \mathrm{mg}$ of MNP. Along with the disappearance of the bare $\mathrm{SiO}_{2}$ NPs, the diameter of MNPs@SiO 2 decreased with increasing quantity of MNP (Figure 3c). However, at high quantity of MNP at $7 \mathrm{mg}$ or $10 \mathrm{mg}$, the TEOS in solution was not enough to produce the silica layer on the surface of all MNPs. ${\mathrm{MNP} @ S i O_{2}}_{2}$ was became irregular shape (Figure 3a). Therefore, $5 \mathrm{mg}$ of MNPs was chosen for further study. 

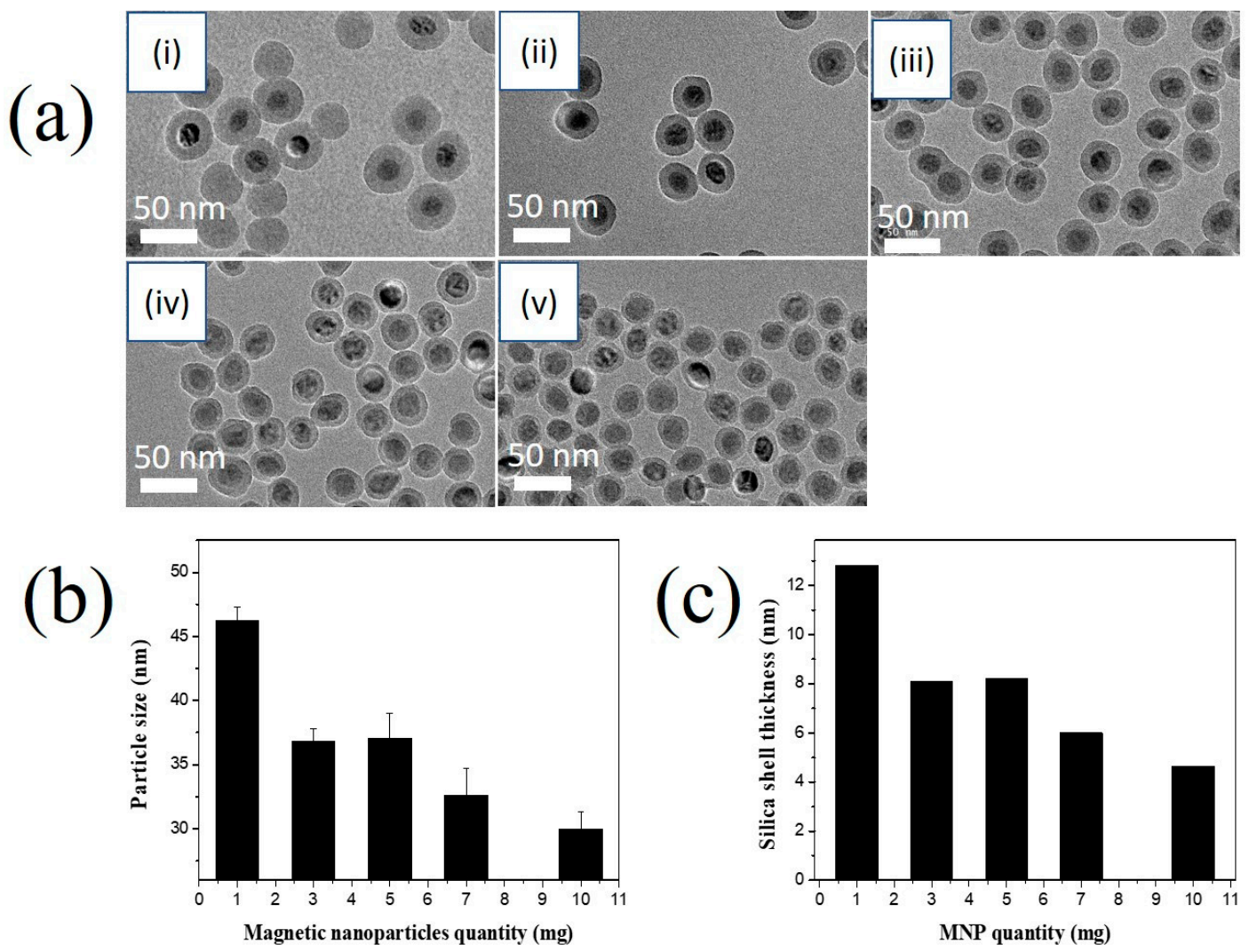

Figure 3. Effects of reverse microemulsion conditions on the silica coating of the magnetic nanoparticles. (a) TEM images (b) particle size and (c) silica shell thickness of $\mathrm{MNP}_{\mathrm{S}} \mathrm{SiO}_{2}$ synthesized at different quantity of MNP: (i) $1 \mathrm{mg}$, (ii) $3 \mathrm{mg}$, (iii) $5 \mathrm{mg}$, (iv) $7 \mathrm{mg}$, and (v) $10 \mathrm{mg}$ in the presence of $0.3 \mathrm{~mL}$ of Igepal ${ }^{\circledR} \mathrm{CO}-520,100 \mu \mathrm{L}$ of TEOS, and $100 \mu \mathrm{L}$ of $\mathrm{NH}_{4} \mathrm{OH}$.

\subsubsection{Effect of TEOS Volume on Silica-Coated Magnetic $\mathrm{Fe}_{3} \mathrm{O}_{4}$ Nanoparticles}

The volume of TEOS precursor is an important factor that affected on the thickness of silica shell of superparamagnetic MNP and the formation of bare $\mathrm{SiO}_{2} \mathrm{NP}$ formation in the solution $[46,48]$. When TEOS is then added to the mixture, it converts to hydrolyzed TEOS adsorbed onto the superparamagnetic MNP surface, which results in transfer of the superparamagnetic MNPs into the water phase [46]. Finally, the hydrolyzed TEOS on the superparamagnetic MNP surface undergoes a condensation reaction to form the silica shell [46]. As the TEOS content increased from 10 to $100 \mu \mathrm{L}$, the diameter of MNPs@SiO 2 and thickness of silica shell on the surface of MNP increased. It reached a plateau at $100 \mu \mathrm{L}$ of TEOS in Figure 4. The silica layer was negligible at $10 \mu \mathrm{L}$, while the silica layer was not uniform at $50 \mu \mathrm{L}$ of TEOS. The $\mathrm{MNP@SiO}_{2}$ with uniform thickness of silica layer

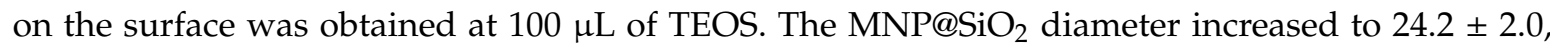
$31.1 \pm 2.3$, and $37.7 \pm 1.4 \mathrm{~nm}$ with 10,50 , and $100 \mu \mathrm{L}$ of TEOS, respectively (Figure $4 \mathrm{~b}$ ). Increasing the volume of TEOS further caused the formation of bare $\mathrm{SiO}_{2} \mathrm{NPs}$, while the diameter of $\mathrm{MNP}_{\mathrm{S}} \mathrm{SiO}_{2}$ was insignificantly different (Figure $4 \mathrm{~b}, \mathrm{c}$ ). So, $100 \mu \mathrm{L}$ of TEOS was chosen for further study. 

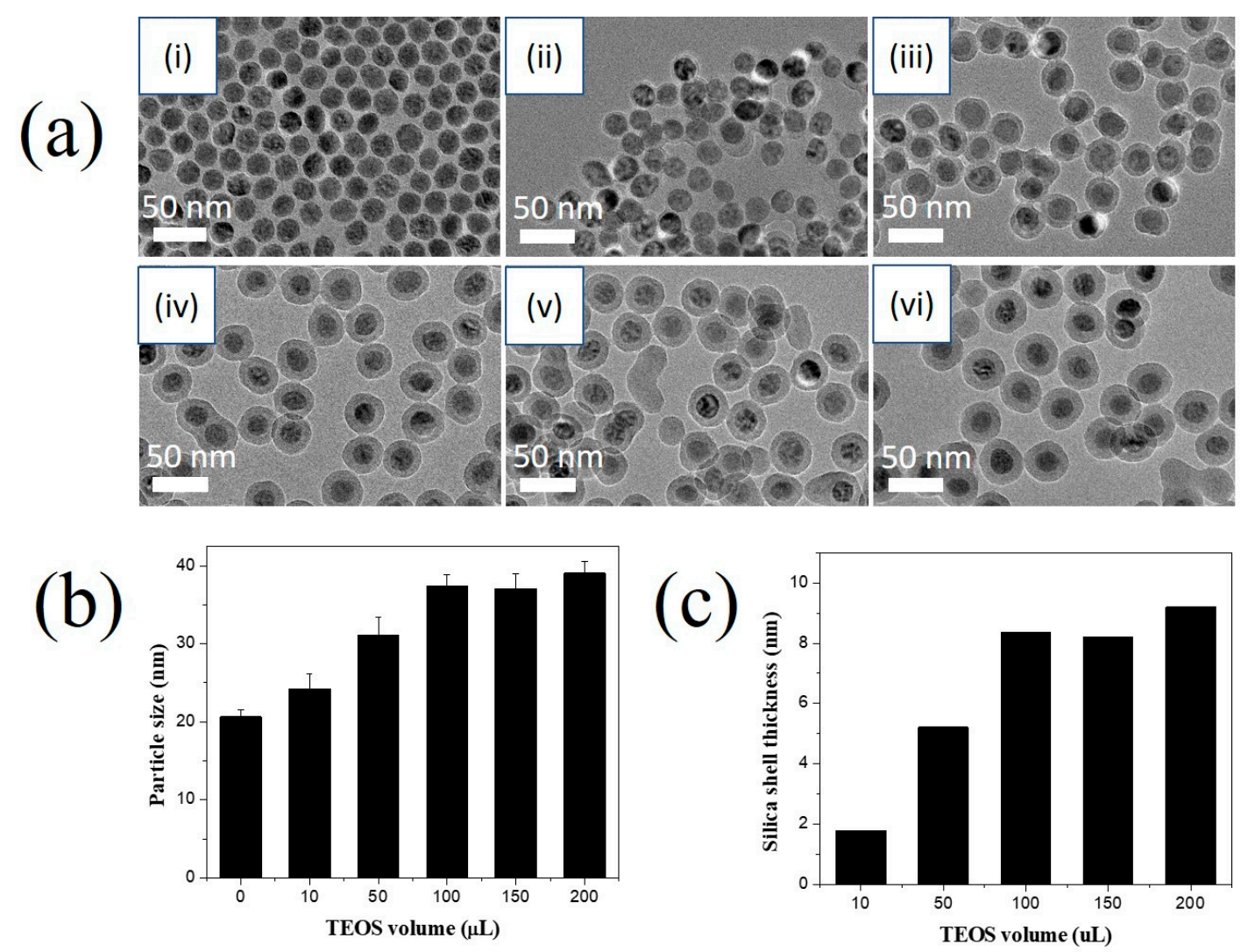

Figure 4. Effects of reverse microemulsion conditions on the silica coating of the magnetic nanoparticles. (a) TEM images (b) particle size and (c) silica shell thickness of ${\mathrm{MNP} @ S i O_{2}}_{2}$ synthesized at different volume of TEOS: (i) $0 \mu \mathrm{L}$, (ii) $10 \mu \mathrm{L}$, (iii) $50 \mu \mathrm{L}$, (iv) $100 \mu \mathrm{L}$, (v) $150 \mu \mathrm{L}$, and (vi) $200 \mu \mathrm{Lin}$ the presence of $0.3 \mathrm{~mL}$ of Igepal ${ }^{\circledR} \mathrm{CO}-520,5 \mathrm{mg}$ of $\mathrm{MNP}$, and $100 \mu \mathrm{L}$ of $\mathrm{NH}_{4} \mathrm{OH}$.

\subsubsection{Effect of GPTS Concentration on Silica-Coated Magnetic $\mathrm{Fe}_{3} \mathrm{O}_{4}$ Nanoparticles}

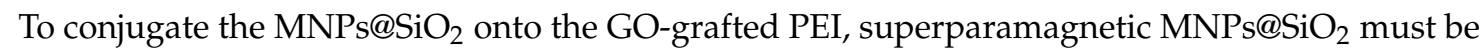

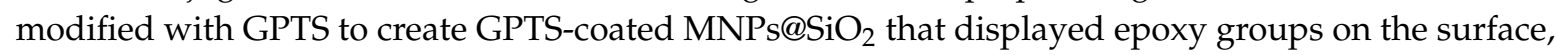
enabling conjugation with the $-\mathrm{NH}_{2}$ groups of PEIs. The superparamagnetic $\mathrm{MNPs} @ \mathrm{SiO}_{2}$ were incubated in a toluene solution containing 1 to $3 \%$ GPTS for $1 \mathrm{~h}$. The diameter remained unchanged and no bare $\mathrm{SiO}_{2}$ was obtained after GPTS treatment (Figure S2). So, 3\% GPTS was chosen for further study.

\subsection{Preparation of Graphene Oxide Grafted Polyethyleneimine (GO-grafted PEI)}

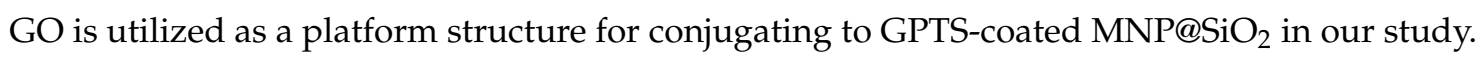
However, GO was easily aggregated in aqueous solution. Therefore, GO was dispersed in solutions of PEI in our study to improve it stability aqueous solution [49-51]. GO was incubated with PEI to enables dispersion of GO in aqueous solutions due to its intrinsic hydrophilicity [52]. Therefore, two sizes of branched PEI (molecular weights of 600 (PEI 600), and 25,000 (PEI 25k) were investigated for GO grafting. In Figure S3, GO was dispersed well in PEI 25k but aggregated in PEI 600, as seen in the optical images. This suggests that the low molecular weight of PEI 600 cannot stabilize and dispersed GO in aqueous solutions. TEM images and the absorbance spectra of PEI 25k grafted GO are shown in Figure S3. PEI grafted GO displays a smoother and flatter surface than bare GO. The absorbance spectra of PEI grafted GO shows a significant increase in absorbance intensity in the UV region (Figure S3), indicating the presence of PEI on the surface of GO.

To increase the linking chain position on the surface, GO was first conjugated with PEI to modify the GO surface with $-\mathrm{NH}_{2}$ groups due to its excellent cationic polymer [53-55]. To confirm that PEI 25k is covalently bound to GO, we used attenuated total reflection-Fourier transform infrared spectroscopy 
(ATR-FTIR) to characterize the functional groups of PEI grafted GO. FTIR spectra of GO, and PEI $25 \mathrm{k}$ grafted GO, are shown in Figure S3. The presence of various oxygen functionalities is present in the GO sample. A broadband and high absorbance intensity from $3000-3700 \mathrm{~cm}^{-1}$ was assigned to the stretching of the hydroxyl group (-OH) [56]. Narrow intense peaks at $1715 \mathrm{~cm}^{-1}$ and $1621 \mathrm{~cm}^{-1}$ represent characteristic stretching of $-\mathrm{COO}^{-}$groups and $\mathrm{C}=\mathrm{C}$ vibration of aromatic chains on the $\mathrm{GO}$ surface. GO also showed peaks at 1352, 1216, 1036, and $974 \mathrm{~cm}^{-1}$ representing the carboxyl/carbonyl, epoxy, and alkoxy groups, respectively [14,56-58].

In contrast, PEI grafted GO exhibited additional peaks at 3100, 2928, and $2821 \mathrm{~cm}^{-1}$, which are attributed to the stretching of amide $\mathrm{B}$ and stretching and bending of $-\mathrm{CH}_{2}$ from PEI. In addition, the disappearance of the $1715 \mathrm{~cm}^{-1}$ peak and occurrence of new peaks at $1640 \mathrm{~cm}^{-1}$ (Amide I) and $1544 \mathrm{~cm}^{-1}$ (Amide II) indicate that the carboxyl groups reacted with the primary amine groups to generate the amide bonds. This result indicates that the conjugation of PEI to the GO surface was successful.

\subsection{Conjugation of Silica-Coated Magnetic Nanoparticles on Graphene Oxide Grafted Polyethyleneimine}

PEI grafted GO was reacted with GPTS-coated MNPs@SiO 2 by incubating $250 \mu \mathrm{g}$ of GPTS-coated MNPs@SiO ${ }_{2}$ with PEI grafted GO (250 to $2500 \mu \mathrm{g}$ ) at weight-to-weight ratios (GO/MNP) of 2:1, 3:1, 4:1, 5:1, 6:1, 8:1, and 10:1 (Figure 5a and Figure S4). At a low GO/MNP ratio, GPTS-coated MNPs@SiO were aggregated on the GO surface and precipitated. At the highest GO/MNP ratio (10:1), the density of MNPs on the GO surface was too low to impart magnetic properties. Overall, the surface density of GPTS-coated MNPs@SiO 2 decreased with increasing GO content. Therefore, a GO/MNP ratio of 5:1 was chosen for subsequent studies.
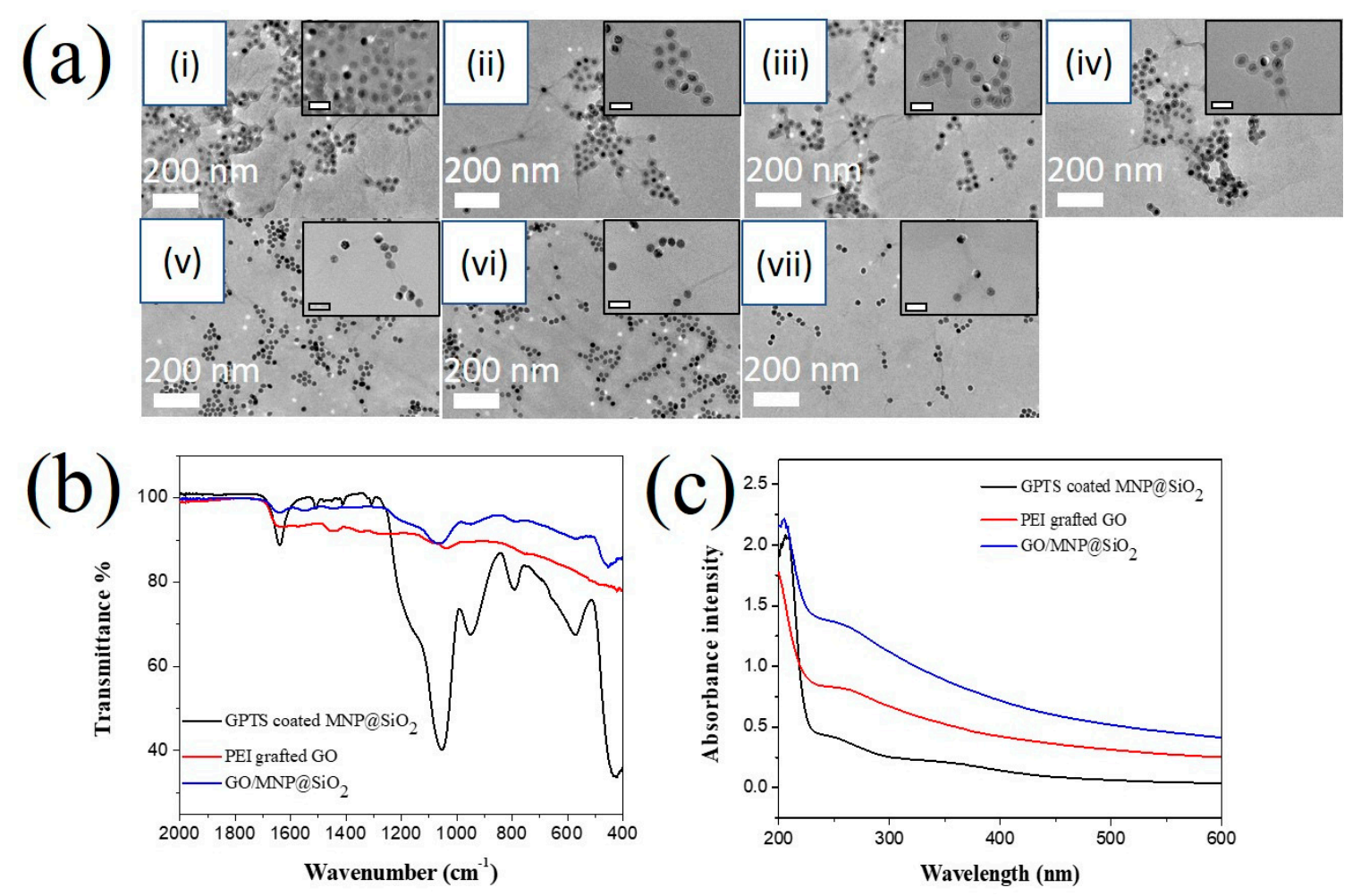

Figure 5. (a) TEM images of GO/MNP@SiO 2 coated with various ratios of PEI grafted GO and GPTS-coated MNP@SiO 2 (i) 2:1, (ii) 3:1, (iii) 4:1, (iv) 5:1, (v) 6:1, (vi) 8:1, and (vii) 10:1. The scale bar in inset is $50 \mathrm{~nm}$. (b) Attenuated total reflection-Fourier transform infrared spectra and (c) UV-Vis spectra of GPTS-coated MNPs@SiO 2 , PEI grafted GO, and GO/MNPs@SiO 2 . 
The conjugation of GPTS-coated MNPs@SiO 2 onto PEI-grafted GO was confirmed by determining the functional groups with ATR-FTIR (Figure 5b). The GPTS-coated MNPs@SiO 2 showed a typical spectrum with peaks at $949 \mathrm{~cm}^{-1}$ and $1053 \mathrm{~cm}^{-1}$ that are attributed to the oxirane group from the GPTS and Si-O from the silica [59]. The intensity ratio of peaks at 949 to $1053 \mathrm{~cm}^{-1}$ is 1.67 . When GPTS-coated MNPs@SiO 2 were conjugated to PEI grafted GO, the peak ratio between 949 to $1053 \mathrm{~cm}^{-1}$ decreased to 1.05. This result indicates that the oxirane peak of GPTS-coated MNPs@SiO reacted with the primary amine groups of PEI. The optical properties of GO/MNP@SiO 2 nanomaterial was showed in Figure 5c. The UV-Vis spectra of GO/MNP@SiO $\mathrm{S}_{2}$ showed the combination properties of both GPTS-coated $\mathrm{MNP} @ S i O_{2}$ with the strong absorbance at 210,250 and $350 \mathrm{~nm}$ and PEI grafted GO at $280 \mathrm{~nm}$. Therefore, GPTS-coated MNPs@SiO 2 were successfully conjugated onto the PEI-grafted GO to generate the GO/MNPs@SiO 2 .

\subsection{The Magnetization and Protein Isolation of Silica-Coated Magnetic Nanoparticles on Graphene Oxide Grafted Polyethyleneimine}

The magnetic property of the GO/MNP@SiO 2 was investigated by using a PPMS-9 vibrating sample magnetometer. The saturation magnetization of the GO/MNPs@SiO 2 was determined to be $9.53 \mathrm{emu} / \mathrm{g}$ at magnetic field of $2.0(\mathrm{~T})$, which is higher than the magnetization of MNPs in previous reports $[40,60]$ (Figure 6a). The magnetization as the function of applied field showed a reversible S-shape and no remnant magnetization is obtained, indicating a superparamagnetic behavior of the GO/MNP@SiO 2 . The magnetic property of the GO/MNPs@SiO $\mathrm{M}_{2}$ was dramatically improved compared to that of MNP in the inset of Figure 6a. After applying of magnet for $5 \mathrm{~min}$, the GO/MNPs@SiO ${ }_{2} \mathrm{was}$ easily collected, while the $\mathrm{MNP@SiO}$ still dispersed in aqueous solution. It indicated that the presence of GO as the platform for conjugating the $\mathrm{MNP@SiO}$ facility the collection of MNP.
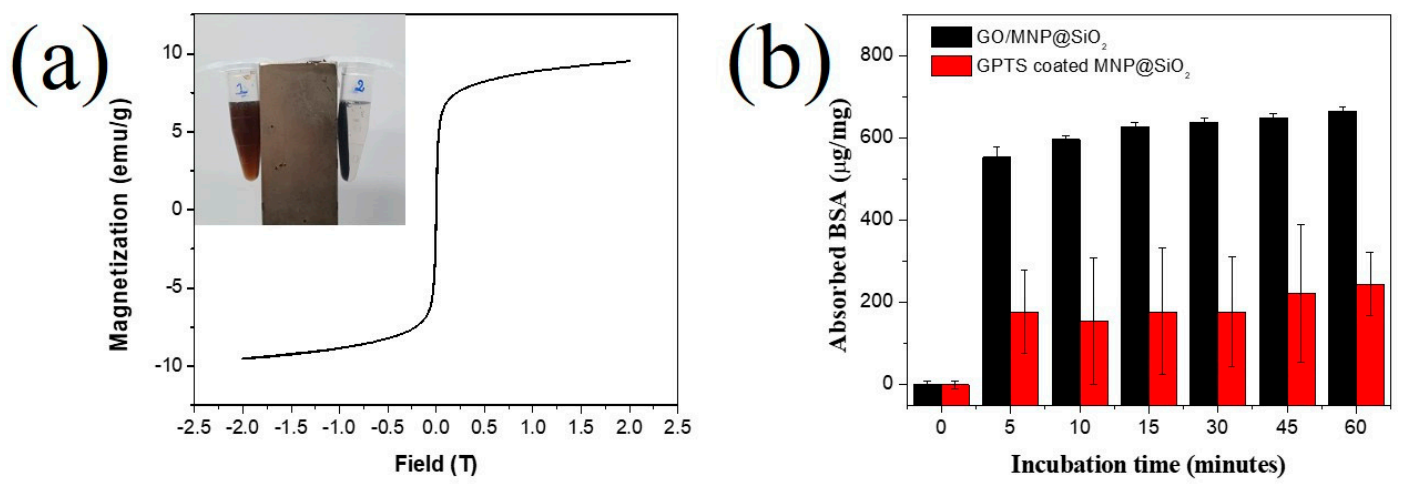

Figure 6. (a) Superparamagnetic hysteresis loop of $\mathrm{GO} / \mathrm{MNP} @ \mathrm{SiO}_{2}$ used to determine saturation magnetization. The inset is photo of GPTS-coated $\mathrm{MNP} @ S i O_{2}$ (left) and GO/MNP@SiO 2 (right) when applying magnet for 5 min. (b) Adsorbed BSA per $1 \mathrm{mg}$ of GO/MNP@SiO 2 and GPTS-coated $\mathrm{MNP} @ S i O_{2}$ incubated at various times.

For application, GO has been shown to be a suitable platform for protein and nucleic acid adsorption [14,61]. However, the separation of GO from solution is a time-consuming and complicated

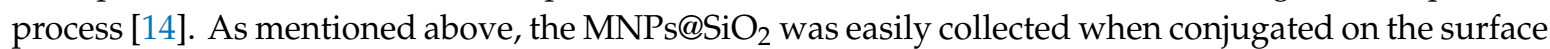
of GO in our study, Therefore, we used the GO/MNPs@SiO $\mathrm{S}_{2}$ nanocomposites with superparamagnetic property as an isolation material to investigate the isolation of protein in solution. BSA is used as a model protein to investigate the isolation ability of the GO/MNPs@SiO ${ }_{2}$ nanocomposites. The GPTS-coated MNP@SiO 2 was utilized as a control material in our study. As shown in Figure S5, BSA solution exhibited an absorbance peak at $280 \mathrm{~nm}$ because of its protein property. This peak was linearly proportional to the BSA concentration in the range of 0 to $100 \mu \mathrm{M}$ (Figure $6 \mathrm{~b}$ ). The quantity of BSA that adsorbed onto the nanomaterials in our study was observed according to the incubation time. According to the previous report, GO is an amphiphile with both hydrophilic edges and hydrophobic 
basal plane [62]. The $\pi-\pi$ stacking interaction between tyrosine or tryptophan residues of BSA and hydrophobic basal plane have an important role for BSA absorbed on GO/MNPs@SiO ${ }_{2}$ [62]. Indeed, BSA adsorbed on $1 \mathrm{mg}$ of GO/MNP@SiO${ }_{2}$ and GPTS-coated ${\mathrm{MNP} @ S i O_{2}}_{2}$ initially increased sharply and achieved a maximum value in Figure $6 \mathrm{~b}$. The capability of adsorbed BSA per mg of GO/MNP@SiO was $628 \pm 9.3 \mu \mathrm{g} / \mathrm{mg}$ after $15 \mathrm{~min}$ incubation, adsorbing $65 \%-69 \%$ of the BSA from solution (Figure $6 \mathrm{~b}$ ). The BSA adsorption capability of GPTS-coated $\mathrm{MNP@SiO}_{2}$ was $178 \pm 154 \mu \mathrm{g} / \mathrm{mg}$, which was 3.5-fold less than that of the GO/MNP@SiO 2 . This result indicates that BSA can be easily adsorbed onto the $\mathrm{GO} / \mathrm{MNP} @ \mathrm{SiO}_{2}$ nanocomposite and collected due to the presence of $\mathrm{GO}$ as a platform and MNP as a magnetic separator material. In our previous report, we used graphene oxide conjugated magnetic beads to extract total RNA and miRNA from non-small cell lung cancer cells [14]. Therefore, we believed that it is also possible to isolate RNA and miRNA from a matrix containing sugars, DNA and other biomolecules by using $\mathrm{GO} / \mathrm{MNP} @ \mathrm{SiO}_{2}$ nanomaterial. In conclusion, this result suggests that the $\mathrm{GO} / \mathrm{MNP} @ \mathrm{SiO}_{2}$ nanostructure can be used for protein and nucleic isolation.

\section{Conclusions}

The silica-coated magnetic iron oxide nanoparticles conjugated to graphene oxide for protein separation were successfully prepared. The silica shell on the superparamagnetic MNPs was optimized by adjusting experimental conditions (300 $\mu \mathrm{L}$ of Igepal ${ }^{\circledR} \mathrm{CO}-520,5 \mathrm{mg}$ of MNP, $100 \mu \mathrm{L}$ of TEOS, and $100 \mu \mathrm{L}$ of $\mathrm{NH}_{4} \mathrm{OH}$ in cyclohexane) to produce $\mathrm{MNPs} @ \mathrm{SiO}_{2}$ with highly saturated magnetization. MNPs@SiO ${ }_{2}$ were incubated with GPTS to produce GPTS-coated MNPs@SiO ${ }_{2}$ with surface functionalized epoxy groups. GO was incubated and covalently conjugated with PEI to enhance the stability of GO in aqueous solution and introduce reactive functional groups. GPTS-coated $\mathrm{MNPs} @ \mathrm{SiO}_{2}$ were conjugated onto the surface of GO-grafted PEI at a GO/MNP ratio of 5 . The saturation superparamagnetization value of the $\mathrm{GO} /{\mathrm{MNP} @ S i \mathrm{O}_{2}}_{2}$ nanocomposite was $9.53 \mathrm{emu} / \mathrm{g}$ at a magnetic field of 2.0 (T). The GO/MNP@SiO ${ }_{2}$ nanocomposite was used to separate BSA from solution. The quantity of BSA adsorbed onto $1 \mathrm{mg}$ of GO/MNP@SiO ${ }_{2}$ increased sharply and achieved a maximum value of $65 \%-69 \%$ after $15 \mathrm{~min}$. This result suggests that the preparation method for GO/MNP@SiO can be used to fabricate nanocomposites for protein isolation.

Supplementary Materials: The following are available online at http://www.mdpi.com/2079-4991/10/1/117/s1. Figure S1. Molecular structure of Igepal ${ }^{\circledR}$ CO-520. Figure S2. Effects of GPTS concentration on the silica coating of the magnetic nanoparticles. (a) TEM images, (b) particle size and (c) silica shell thickness of $\mathrm{MNP}_{\mathrm{SiO}}$ synthesized at different GPTS concentrations: (i) $0 \%$, (ii) $1 \%$, (iii) $2 \%$, (iv) $3 \%$, and (v) $5 \%$ in the presence of $0.3 \mathrm{~mL}$ of Igepal ${ }^{\circledR} \mathrm{CO}-520,5 \mathrm{mg}$ of MNP, $100 \mu \mathrm{L}$ of TEOS and $100 \mu \mathrm{L}$ of $\mathrm{NH}_{4} \mathrm{OH}$. Figure S3. (a) Optical images of GO incubated with PEI 600, PEI 25k. (b) TEM images, (c) UV-Vis absorbance and (d) ATR-FTIR of (i) GO and (ii) PEI 25k-grafted GO. Figure S4. Absorbance spectra of GO/MNP@SiO $\mathrm{M}_{2}$ with various ratios of PEI-grafted GO and GPTS-coated MNP@SiO ${ }_{2}$, (i) 2:1, (ii) 3:1, (iii) 4:1, (iv) 5:1, (v) 6:1, (vi) 8:1 and (vii) 10:1. Figure S5. (a) Absorbance spectra and (b) calibration curves of BSA protein at different concentrations.

Author Contributions: X.-H.P. and B.-H.J. conceived and designed the experiments. X.-H.P., E.H., H.-M.K., J.A. and A.J. performed the experiments. X.-H.P., and E.H. analyzed the data. T.A.T.T. and D.Q.N. contributed reagents/materials/analysis tools. X.-H.P., B.S.S. and B.-H.J. wrote the paper. B.-H.J. supervised. All authors have read and agreed to the published version of the manuscript.

Funding: This work was supported by the KU Research Professor Program of Konkuk University and funded by Science, ICT \& Future Planning (NRF 2016M3A9B6918892), and ministry of Science and ICT (NRF-2019R1G1A1006488).

Acknowledgments: The authors are grateful for the financial support from the NRF of Korea. Further, the author thanks the financial support by Konkuk University.

Conflicts of Interest: The authors declare no conflicts of interest. 


\section{References}

1. Ghosal, K.; Sarkar, K. Biomedical applications of graphene nanomaterials and beyond. ACS Biomater. Sci. Eng. 2018, 4, 2653-2703. [CrossRef]

2. Lu, Y.-H.; Zhou, M.; Zhang, C.; Feng, Y.-P. Metal-embedded graphene: A possible catalyst with high activity. J. Phys. Chem. C 2009, 113, 20156-20160. [CrossRef]

3. Wang, B.; Chang, Y.-H.; Zhi, L.-J. High yield production of graphene and its improved property in detecting heavy metal ions. New Carbon Mater. 2011, 26, 31-35. [CrossRef]

4. Zhao, X.; Hayner, C.M.; Kung, M.C.; Kung, H.H. Flexible holey graphene paper electrodes with enhanced rate capability for energy storage applications. ACS Nano 2011, 5, 8739-8749. [CrossRef] [PubMed]

5. Liu, K.; Zhang, J.-J.; Cheng, F.-F.; Zheng, T.-T.; Wang, C.; Zhu, J.-J. Green and facile synthesis of highly biocompatible graphene nanosheets and its application for cellular imaging and drug delivery. J. Mater. Chem. 2011, 21, 12034-12040. [CrossRef]

6. Lu, Y.; Lyu, H.; Richardson, A.G.; Lucas, T.H.; Kuzum, D. Flexible neural electrode array based-on porous graphene for cortical microstimulation and sensing. Sci. Rep. 2016, 6, 33526. [CrossRef]

7. Wang, J. Electrochemical glucose biosensors. Chem. Rev. 2008, 108, 814-825. [CrossRef]

8. Sayyar, S.; Murray, E.; Thompson, B.C.; Gambhir, S.; Officer, D.L.; Wallace, G.G. Covalently linked biocompatible graphene/polycaprolactone composites for tissue engineering. Carbon 2013, 52, 296-304. [CrossRef]

9. Kumar, S.; Raj, S.; Sarkar, K.; Chatterjee, K. Engineering a multi-biofunctional composite using poly(ethylenimine) decorated graphene oxide for bone tissue regeneration. Nanoscale 2016, 8, 6820-6836. [CrossRef]

10. Sarkar, K.; Madras, G.; Chatterjee, K. Dendron conjugation to graphene oxide using click chemistry for efficient gene delivery. RSC Adv. 2015, 5, 50196-50211. [CrossRef]

11. Sheng, Y.; Tang, X.; Peng, E.; Xue, J. Graphene oxide based fluorescent nanocomposites for cellular imaging. J. Mater. Chem. B 2013, 1, 512-521. [CrossRef]

12. Zhang, L.; Xia, J.; Zhao, Q.; Liu, L.; Zhang, Z. Functional graphene oxide as a nanocarrier for controlled loading and targeted delivery of mixed anticancer drugs. Small 2010, 6, 537-544. [CrossRef]

13. Lee, W.C.; Lim, C.H.Y.X.; Shi, H.; Tang, L.A.L.; Wang, Y.; Lim, C.T.; Loh, K.P. Origin of enhanced stem cell growth and differentiation on graphene and graphene oxide. ACS Nano 2011, 5, 7334-7341. [CrossRef]

14. Pham, X.-H.; Baek, A.; Kim, T.H.; Lee, S.H.; Rho, W.-Y.; Chung, W.-J.; Kim, D.-E.; Jun, B.-H. Graphene oxide conjugated magnetic beads for RNA extraction. Chem. Asian J. 2017, 12, 1883-1888. [CrossRef] [PubMed]

15. Dulińska-Litewka, J.; Łazarczyk, A.; Hałubiec, P.; Szafrański, O.; Karnas, K.; Karewicz, A. Superparamagnetic iron oxide nanoparticles-Current and prospective medical applications. Materials 2019, 12, 617. [CrossRef] [PubMed]

16. Kodama, R.H. Magnetic nanoparticles. J. Magn. Magn. Mater. 1999, 200, 359-372. [CrossRef]

17. Mahmoudi, M.; Sant, S.; Wang, B.; Laurent, S.; Sen, T. Superparamagnetic iron oxide nanoparticles (SPIONs): Development, surface modification and applications in chemotherapy. Adv. Drug Deliv. Rev. 2011, 63, $24-46$. [CrossRef]

18. Laurent, S.; Saei, A.A.; Behzadi, S.; Panahifar, A.; Mahmoudi, M. Superparamagnetic iron oxide nanoparticles for delivery of therapeutic agents: Opportunities and challenges. Expert Opin. Drug Deliv. 2014, 11, 1449-1470. [CrossRef]

19. Wahajuddin, S.A. Superparamagnetic iron oxide nanoparticles: Magnetic nanoplatforms as drug carriers. Int. J. Nanomed. 2012, 7, 3445-3471. [CrossRef]

20. Yang, H.-H.; Zhang, S.-Q.; Chen, X.-L.; Zhuang, Z.-X.; Xu, J.-G.; Wang, X.-R. Magnetite-containing spherical silica nanoparticles for biocatalysis and bioseparations. Anal. Chem. 2004, 76, 1316-1321. [CrossRef]

21. Im, S.H.; Herricks, T.; Lee, Y.T.; Xia, Y. ACS Biomaterials Science \& Engineering Synthesis and characterization of monodisperse silica colloids loaded with superparamagnetic iron oxide nanoparticles. Chem. Phys. Lett. 2005, 401, 19-23. [CrossRef]

22. Bai, S.; Shen, X. Graphene-inorganic nanocomposites. RSC Adv. 2012, 2, 64-98. [CrossRef]

23. Zhang, W.; Shi, X.; Zhang, Y.; Gu, W.; Li, B.; Xian, Y. Synthesis of water-soluble magnetic graphene nanocomposites for recyclable removal of heavy metal ions. J. Mater. Chem. A 2013, 1, 1745-1753. [CrossRef] 
24. Zhu, J.; Wei, S.; Gu, H.; Rapole, S.B.; Wang, Q.; Luo, Z.; Haldolaarachchige, N.; Young, D.P.; Guo, Z. One-pot synthesis of magnetic graphene nanocomposites decorated with core@double-shell nanoparticles for fast chromium removal. Environ. Sci. Technol. 2012, 46, 977-985. [CrossRef]

25. Yao, Y.; Miao, S.; Liu, S.; Ma, L.P.; Sun, H.; Wang, S. Synthesis, characterization, and adsorption properties of magnetic $\mathrm{Fe}_{3} \mathrm{O}_{4} @$ graphene nanocomposite. Chem. Eng. J. 2012, 184, 326-332. [CrossRef]

26. Tang, D.; Tang, J.; Li, Q.; Su, B.; Chen, G. Ultrasensitive aptamer-based multiplexed electrochemical detection by coupling distinguishable signal tags with catalytic recycling of DNase I. Anal. Chem. 2011, 83, 7255-7259. [CrossRef]

27. Lin, C.-W.; Wei, K.-C.; Liao, S.-S.; Huang, C.-Y.; Sun, C.-L.; Wu, P.-J.; Lu, Y.-J.; Yang, H.-W.; Ma, C.-C.M. A reusable magnetic graphene oxide-modified biosensor for vascular endothelial growth factor detection in cancer diagnosis. Biosens. Bioelectron. 2015, 67, 431-437. [CrossRef]

28. Lin, Y.; Zhou, Q.; Li, J.; Shu, J.; Qiu, Z.; Lin, Y.; Tang, D. Magnetic graphene nanosheet-based microfluidic device for homogeneous real-time electronic monitoring of pyrophosphatase activity using enzymatic hydrolysate-induced release of copper ion. Anal. Chem. 2016, 88, 1030-1038. [CrossRef]

29. Wang, J.; Li, J.; Yan, G.; Gao, M.; Zhang, X. Preparation of a thickness-controlled Mg-MOFs-based magnetic graphene composite as a novel hydrophilic matrix for the effective identification of the glycopeptide in the human urine. Nanoscale 2019, 11, 3701-3709. [CrossRef]

30. Sharafeldin, M.; Bishop, G.W.; Bhakta, S.; El-Sawy, A.; Suib, S.L.; Rusling, J.F. $\mathrm{Fe}_{3} \mathrm{O}_{4}$ nanoparticles on graphene oxide sheets for isolation and ultrasensitive amperometric detection of cancer biomarker proteins. Biosens. Bioelectron. 2017, 91, 359-366. [CrossRef]

31. Ye, N.; Xie, Y.; Shi, P.; Gao, T.; Ma, J. Synthesis of magnetite/graphene oxide/chitosan composite and its application for protein adsorption. Mater. Sci. Eng. C 2014, 45, 8-14. [CrossRef] [PubMed]

32. Yin, P.; Sun, N.; Deng, C.; Li, Y.; Zhang, X.; Yang, P. Facile preparation of magnetic graphene double-sided mesoporous composites for the selective enrichment and analysis of endogenous peptides. Proteomics 2013, 13, 2243-2250. [CrossRef] [PubMed]

33. Yan, H.; Xu, Y.; Lu, Y.; Xing, W. Reduced graphene oxide-based solid-phase extraction for the enrichment and detection of microRNA. Anal. Chem. 2017, 89, 10137-10140. [CrossRef] [PubMed]

34. Shi, X.; Gong, H.; Li, Y.; Wang, C.; Cheng, L.; Liu, Z. Graphene-based magnetic plasmonic nanocomposite for dual bioimaging and photothermal therapy. Biomaterials 2013, 34, 4786-4793. [CrossRef]

35. Cong, H.-P.; He, J.-J.; Lu, Y.; Yu, S.-H. Water-soluble magnetic-functionalized reduced graphene oxide sheets: In situ synthesis and magnetic resonance imaging applications. Small 2010, 6, 169-173. [CrossRef]

36. Yang, X.; Zhang, X.; Ma, Y.; Huang, Y.; Wang, Y.; Chen, Y. Superparamagnetic graphene oxide- $\mathrm{Fe}_{3} \mathrm{O}_{4}$ nanoparticles hybrid for controlled targeted drug carriers. J. Mater. Chem. 2009, 19, 2710-2714. [CrossRef]

37. Shen, J.; Hu, Y.; Shi, M.; Li, N.; Ma, H.; Ye, M. One step synthesis of graphene oxide-magnetic nanoparticle composite. J. Phys. Chem. C 2010, 114, 1498-1503. [CrossRef]

38. Szabó, T.; Bakandritsos, A.; Tzitzios, V.; Devlin, E.; Petridis, D.; Dékány, I. Magnetically modified single and turbostratic stacked graphenes from Tris(2,2'-bipyridyl) Iron(II) Ion-Exchanged Graphite Oxide. J. Phys. Chem. B 2008, 112, 14461-14469. [CrossRef]

39. He, F.; Fan, J.; Ma, D.; Zhang, L.; Leung, C.; Chan, H.L. The attachment of $\mathrm{Fe}_{3} \mathrm{O}_{4}$ nanoparticles to graphene oxide by covalent bonding. Carbon 2010, 48, 3139-3144. [CrossRef]

40. Zhang, Y.; Chen, B.; Zhang, L.; Huang, J.; Chen, F.; Yang, Z.; Yao, J.; Zhang, Z. Controlled assembly of $\mathrm{Fe}_{3} \mathrm{O}_{4}$ magnetic nanoparticles on graphene oxide. Nanoscale 2011, 3, 1446-1450. [CrossRef]

41. Borlido, L.; Azevedo, A.M.; Roque, A.C.A.; Aires-Barros, M.R. Magnetic separations in biotechnology. Biotechnol. Adv. 2013, 31, 1374-1385. [CrossRef] [PubMed]

42. Deng, Y.-H.; Wang, C.-C.; Hu, J.-H.; Yang, W.-L.; Fu, S.-K. Investigation of formation of silica-coated magnetite nanoparticles via sol-gel approach. Colloid Surf. A Phys. Eng. Asp. 2005, 262, 87-93. [CrossRef]

43. Morel, A.-L.; Nikitenko, S.I.; Gionnet, K.; Wattiaux, A.; Lai-Kee-Him, J.; Labrugere, C.; Chevalier, B.; Deleris, G.; Petibois, C.; Brisson, A.; et al. Sonochemical approach to the synthesis of $\mathrm{Fe}_{3} \mathrm{O}_{4} @ \mathrm{SiO}_{2}$ core-shell nanoparticles with tunable properties. ACS Nano 2008, 2, 847-856. [CrossRef] [PubMed]

44. Stöber, W.; Fink, A.; Bohn, E. Controlled growth of monodisperse silica spheres in the micron size range. J. Colloid Interface Sci. 1968, 26, 62-69. [CrossRef] 
45. Zhang, M.; Cushing, B.L.; O'Connor, C.J. Synthesis and characterization of monodisperse ultra-thin silica-coated magnetic nanoparticles. Nanotechnology 2008, 19, 085601. [CrossRef]

46. Ding, H.L.; Zhang, Y.X.; Wang, S.; Xu, J.M.; Xu, S.C.; Li, G.H. $\mathrm{Fe}_{3} \mathrm{O}_{4} @ \mathrm{SiO}_{2}$ Core/Shell nanoparticles: The silica coating regulations with a single core for different core sizes and shell thicknesses. Chem. Mater. 2012, 24, 4572-4580. [CrossRef]

47. Ghosh, S.K.; Khatua, P.K.; Bhattacharya, S.C. Aggregation of non ionic surfactant igepal in aqueous solution: Fluorescence and light scattering studies. Int. J. Mol. Sci. 2003, 4, 562-571. [CrossRef]

48. Noval, V.E.; Carriazo, J.G. $\mathrm{Fe}_{3} \mathrm{O}_{4}-\mathrm{TiO}_{2}$ and $\mathrm{Fe}_{3} \mathrm{O}_{4}-\mathrm{SiO}_{2}$ core-shell powders synthesized from industrially processed magnetite $\left(\mathrm{Fe}_{3} \mathrm{O}_{4}\right)$ microparticles. Mater. Res. 2019, 22, e20180660. [CrossRef]

49. Li, D.; Müller, M.B.; Gilje, S.; Kaner, R.B.; Wallace, G.G. Processable aqueous dispersions of graphene nanosheets. Nat. Nanotechnol. 2008, 3, 101. [CrossRef]

50. Yang, S.-T.; Chang, Y.; Wang, H.; Liu, G.; Chen, S.; Wang, Y.; Liu, Y.; Cao, A. Folding/aggregation of graphene oxide and its application in $\mathrm{Cu}^{2+}$ removal. J. Colloid Interface Sci. 2010, 351, 122-127. [CrossRef]

51. Deng, D.; Jiang, X.; Yang, L.; Hou, X.; Zheng, C. Organic solvent-free cloud point extraction-like methodology using aggregation of graphene oxide. Anal. Chem. 2014, 86, 758-765. [CrossRef] [PubMed]

52. Geng, J.; Yin, Y.; Liang, Q.; Zhu, Z.; Luo, H. Polyethyleneimine cross-linked graphene oxide for removing hazardous hexavalent chromium: Adsorption performance and mechanism. Chem. Eng. J. 2019, 361, 1497-1510. [CrossRef]

53. Chen, B.; Liu, M.; Zhang, L.; Huang, J.; Yao, J.; Zhang, Z. Polyethylenimine-functionalized graphene oxide as an efficient gene delivery vector. J. Mater. Chem. 2011, 21, 7736-7741. [CrossRef]

54. Feng, L.; Zhang, S.; Liu, Z. Graphene based gene transfection. Nanoscale 2011, 3, 1252-1257. [CrossRef] [PubMed]

55. Zhang, L.; Lu, Z.; Zhao, Q.; Huang, J.; Shen, H.; Zhang, Z. Enhanced chemotherapy efficacy by sequential delivery of siRNA and anticancer drugs using PEI-grafted graphene oxide. Small 2011, 7, 460-464. [CrossRef] [PubMed]

56. Choi, E.-Y.; Han, T.H.; Hong, J.; Kim, J.E.; Lee, S.H.; Kim, H.W.; Kim, S.O. Noncovalent functionalization of graphene with end-functional polymers. J. Mater. Chem. 2010, 20, 1907-1912. [CrossRef]

57. Ren, P.-G.; Yan, D.-X.; Ji, X.; Chen, T.; Li, Z.-M. Temperature dependence of graphene oxide reduced by hydrazine hydrate. Nanotechnology 2010, 22, 055705. [CrossRef]

58. Xu, Y.; Bai, H.; Lu, G.; Li, C.; Shi, G. Flexible graphene films via the filtration of water-soluble noncovalent functionalized graphene sheets. J. Am. Chem. Soc. 2008, 130, 5856-5857. [CrossRef]

59. Ma, S.; Liu, W.; Wei, Z.; Li, H. Mechanical and thermal properties and morphology of epoxy resins modified by a silicon compound. J. Macromol. Sci. A 2010, 47, 1084-1090. [CrossRef]

60. Pham, X.-H.; Kyeong, S.; Jang, J.; Kim, H.-M.; Kim, J.; Jung, S.; Lee, Y.-S.; Jun, B.-H.; Chung, W.-J. Facile method for preparation of silica coated monodisperse superparamagnetic microspheres. J. Nanomater. 2016, 2016, 9. [CrossRef]

61. Lu, C.-H.; Yang, H.-H.; Zhu, C.-L.; Chen, X.; Chen, G.-N. A graphene platform for sensing biomolecules. Angew. Chem. Int. Ed. 2009, 48, 4785-4787. [CrossRef] [PubMed]

62. Chen, X.; Hai, X.; Wang, J. Graphene/graphene oxide and their derivatives in the separation/isolation and preconcentration of protein species: A review. Anal. Chim. Acta 2016, 922, 1-10. [CrossRef] [PubMed]

(C) 2020 by the authors. Licensee MDPI, Basel, Switzerland. This article is an open access article distributed under the terms and conditions of the Creative Commons Attribution (CC BY) license (http://creativecommons.org/licenses/by/4.0/). 